\title{
Exploring Teaching Learning Process in DeVeloping Higher ORDER THINKING SKILl (HOTS) TO HIGHER SECONDARY SCHOOL (SMA) StUdents in PontianaK
}

\author{
Clarry Sada \\ University of Tanjungpura, Pontianak, Indonesia \\ E-mail: jawa1508@yahoo.com
}

\begin{abstract}
This study focuses on the Teaching Learning (TL) process in developing Higher Order Thinking Skill to SMA Students which is done by the secondary school teachers in Pontianak City. The National Curriculum, namely, Curriculum 2013, well known by its' abbreviation C-13, has got some significant revisions. Among those revisions, the aspect of critical thinking which emphasizes higher order thinking skill (HOTS) became the concern. The curriculum has arranged the procedures and principles of HOTS. As mentioned that the C-13 should be in line with the global competencies, thus, the teachers should understand and implement them in their teaching process. Thus, in this study, the researcher intends to explore the teachers' knowledge and how the implementation of curriculum 2013 in the teachinglearning process. In exploring these matters, the main instrument used is questionnaires. The questionnaires contained 21 items which were focused on exploring teachers' current knowledge about curriculum 2013, the implementation of a teaching-learning process and understood the procedures of HOTS. There were 31 English teachers as the subject of this study. The results show that (1) understand vision and mission of C-13 (73\%, (2) implementing a process of HOTS (36\%), (3) understand characteristics of critical thinking (55\%) and (4) understand models of teaching (45\%). Thus, the knowledge about C-13 with its principles on HOTS is averagely good.
\end{abstract}

Keywords: Curriculum 2013; HOTS; Developing

\section{INTRODUCTION}

Some public schools have applied curriculum 2013. The Indonesian government realizes that some changes to the new curriculum would bring some various opinions. But the goal of the revision of curriculum 2006 to be curriculum 2013 is to bring the Indonesian education to be better. This curriculum offers some progress from the former curriculum. For example, curriculum 2013 gives some strategies for teachers and students. Teachers will be more creative, while students will be more active.

In a new curriculum, it applies a scientific approach. Teachers will not only teach but also facilitate students. So, the teachers are demanded to be more creative in doing their teaching activities. At the same time, the 2013 curriculum (C-13) has offered some models. The presence of C-13 is as a replacement and further development of the previous 2006 curriculum (competence-based curriculum). Curriculum 2013 is arranged to help and develop the students' potential, face the developing of an era, and response to the students' needs.
In term of assessment, the current curriculum has mentioned some alternatives for assessment, such as the teachers are encouraged to use an authentic assessment because it could assess more aspects of students' characteristics. The previous curriculum (2006 curriculum) did not suggest clearly how to assess or evaluate the students' works. Thus, the 2013 curriculum was officially launched to be implemented in the school year 2013/2014 by the Ministry of Education and Culture, while in the Ministry of Religion was begun in July 2014.

The challenges of education in the technology era are the mastery of technology devices. Those devices are so much needed by the teachers to transfer and explain knowledge of their lessons. In this context, the $\mathrm{C}-13$ has given guidelines about those aspects. In line with these factors, it should exist in the teaching and learning process. The better competences would have better teaching should be presented by professional teachers.

Challenges in teaching and learning in this technology era are becoming complicated because the changes in the environment have influenced the learners' perceptions, ideas, and characters. Challenges in teaching and learning in this 
technology era are more complicated because the learners should gain and improve knowledge, behaviors and psychomotor. The global skills mentioned in C-13, such as critical thinking, creative/innovative, communication and collaboration (4Cs). The C-13's end is preparing the millennial generations in facing the tough challenges and competitions in the future. Those changes include changes in society, such as social, culture, technology and ways of life. Therefore, the curriculum should cover those aspects and as guidelines for school to manage the future.

Meaningful learning is about making a connection between what the learners have already known and the new information that we would like the learners to know (Ausubel, 1978). In other words, we need to help learners to activate what they have already known about and what we are going to teach as new information. Therefore, we help them to gain information to their existing knowledge. The implementation of a learning process, teachers should be able to develop thinking skill, logical reasoning and understand the self-conception of the learners. In this case, learning has meaning and achieve better results.

The ability of critical thinking should be a target of learning and formed as the thinking culture. In America, thinking skill has disseminated to the students of all levels. This matter is in line with the objectives of the 2013 curriculum.

The current revision of the 2013 curriculum stresses building a thinking culture. As mentioned by Anderson \& Karthwol (2001), thinking skill is classified into three levels, such as lower order (LOTS), moderate order (MOTS) and higher order (HOTS). The current revision of the 2013 curriculum, focuses on building a thinking culture. As mentioned the skill is so much needed for twenty-firstcentury competence.

Critical thinking is one of the most sought-after skills in almost every industry and every workplace. It refers to the ability to analyze information objectively and make a reasoned judgment. Critical thinking involves the evaluation of sources such as data, facts, observable phenomenon, and research findings. Good critical thinkers can draw reasonable conclusions from a set of information and discriminate between useful and less useful details to solve a problem or make a decision.

Another definition says, "critical thinking is thinking that makes sense and focused reflection to decide what should be believed or done" (Robert Ennis in Fisher, 2008:4). This opinion meant that the nature of thinking is the human activity to use his thinking skill intellectually when there is a problem, and at the same, he was searching for an alternative of solutions, thus finally, he could make a decision. The decision making has done when a man is thinking, while thinking should be a part of critical thinking.

The roles and the importance of critical thinking skill in developing human resources to be creative and innovative which generate productive human resources, therefore, critical thinking culture should be built continuously to school children. In implementing this skill, the 2013 curriculum has proposed some learning models, such as discovery learning, problem-based learning, project-based learning, and inquiry learning. Thus, in this study, the researcher intended to explore the English language teachers' efforts to practice HOTS and those learning models. The questionnaires are used to obtain the data of the research.

A 2015 report by the Foundation for Young Australians claims a demand for critical thinking skills in new graduates has risen $158 \%$ in three years. The data had drawn from an analysis of 4.2 million online job postings from 6,000 different sources in the period 2012-2015 (Davies, 2017). The data obtained from the questionnaires have reflected the students' responses to the research questions of the learning process, the frequency of giving assignments and using teaching models that reflected HOTS.

\section{Methodology}

The study aims at exploring the teaching-learning process in developing HOTS to the senior secondary school students. The research subjects were the 31 English language teachers, who were active teachers both at the state and private secondary schools in Pontianak. The data were obtained mainly by responding to the 21 items of questionnaires. Those data were analyzed and subsequently displayed narratively.

\section{RESULTS AND DISCUSSION}

\section{A. Results}

\section{1) General Description of Respondents}

Respondents were all English language teachers of Senior High Schools of Pontianak, West Kalimantan. The respondents were taken randomly and without considering their length of teaching services, having attended training on C-13 and other attributes.

\section{2) Implementation of the 2013 Curriculum}

From the data obtained, there were nine schools had implemented the 2013 curriculum. The teachers from those schools got the information on the implementation the curriculum had three categories, such as a) had attended socialization, workshop/training, at least once, b) by reading books/articles about the curriculum, and 3) information from colleague teachers. While the teachers from the schools that did not implement the curriculum yet also had attended socialization once about the curriculum.

\section{3) Own Curriculum 2013}

However, those teachers, who had implemented or not, had possessed the curriculum as follows: $55 \%$ almost complete, $27 \%$ partially, and $18 \%$ not possess. Some of the respondents did not understand the vision and missions of the curriculum because of not possessed curriculum and teacher's guidebook. 


\section{4) Knowledge of Teaching Models}

Some of the teachers were not so familiar with the teaching models mentioned in the curriculum, such as discovery learning, problem-based learning, and projectbased learning. Therefore, they did not apply this model and most of them $(71 \%)$ response wrongly about the characteristics of those teaching models.

\section{5) Understand Procedures of Critical Thinking}

In $\mathrm{C}-13$, it mentioned about the $21^{\text {st }}$-century skills to be learned and mastered by the learners, i.e. critical thinking, creative/innovative, communication and collaboration. Among those skills, critical thinking is the main focus. Most of the respondents (75\%) stated that they were on the process of understanding the principles of HOTS.

Meanwhile, the frequency of giving tasks and teachinglearning process with the principles of HOTS had not frequently applied in the classroom activities. Though they had tried to do so, however, they were not sure whether they had practiced the principles of HOTS.

As mentioned earlier, the respondents had not sure about the application of the teaching models, therefore they frequently implemented those models. If they did, but they did not sure about their model whether it reflected critical thinking.

\section{B. Discussion}

\section{Profession and Professional Development}

The profession has defined as an occupation requiring special training in the liberal arts or sciences, especially one of the three learned professions, law, theology, or medicine. In education, the profession has defined as a job which needs the expertise to apply techniques of teaching and high dedication to the job (UU RI, 2005).

A profession is a vocation founded upon specialized educational training, a purpose of which is to supply disinterested objective counsel, service to others for direct and definite compensation, and wholly apart from an expectation of another business gain.

Professional Development and Standards for Professional Learning are intended to guide relevant and valuable professional learning opportunities-which are essential to the professional growth of all educators.

From the above explanation, the profession is an occupation that requires expertise, skills and knowledge. In the broadest sense, the education profession has to understand the education standards-Indonesian National Standards of Education (SNP). Meanwhile, professional in education refers to a wide variety of specialized training, formal education, and advanced professional learning to help administrators, teachers, and other educators in improving their professional knowledge, competence, skill, and effectiveness.

Referring to the definition of profession and professional, the teachers should have several training to develop their expertise, competencies, and skill which will support them to do the task or job professionally. In this study, the data showed that some teachers have insufficient training, knowledge, and skills. Those limitations had caused by lacks of training/workshops and minimal opportunities to attend professional education.

According to Teacher and Lecturer's regulations (UU RI, 2005), the teacher is a professional educator with several tasks/duties, such as teaching/educating, guiding, counseling, directing, training, assessing and evaluating learners at all levels in formal education. Therefore, there might be teachers who never got professional training to upgrade their competence and skill which are relevant to their tasks as teachers.

The thinking skill has been a crucial matter for educators, scientists, and practitioners of education. It seemed difficult to develop one's mind active because of the absence of knowledge and relationship. Learners of insufficient knowledge tried to keep quiet because they were unable to involve in the discussion. Because of this weakness, thinking did not happen as a result of insufficient knowledge, therefore, the main problem was how to activate thinking through mind changing. Mind activities might active after several meeting with other people as a process of reopening the black box.

\section{Skill Culture of Critical Thinking}

Critical thinking is one of the most sought-after skills in almost every industry and every workplace. What is critical thinking? It refers to the ability to analyze information objectively and make a reasoned judgment. (Doyle, 2018).

Early (2003) states that critical thinking is the intellectually disciplined process of actively and skillfully conceptualizing, applying, analyzing, synthesizing, and evaluating information generated by observation, experience, reflection, reasoning, or communication, as a guide to belief and action. Critical thinking has interwoven modes of scientific, mathematical, historical, anthropological, economic, moral, and philosophical.

In $\mathrm{C}-13$ was stated that the $21^{\text {st }}$-century competence is critical thinking, creative/innovative, communication and collaboration. These four elements should be understood well by the learners. However, the results of questionnaires, some teachers still confused about the implementation of them in the teaching-learning process. Of course, before the teachers could apply in their teaching, they must know well about these elements.

Development in thinking requires a gradual process requiring plateaus of learning and just plain hard work. It is not possible to become an excellent thinker simply because of one will it. Changing one's habits of thought is a longrange project, happening over years, not weeks or months. The essential traits of a critical thinker require an extended period of development.

To anticipate the challenges of the third millennium, Indonesian human resources require to become individuals who have competitive advantages in the globalized world. One of the efforts of producing such generation is through education with teachers and their credentials. Through the modification of the recent curriculum, the Indonesian 
government has done its best to prepare students of all levels of education to be prospective citizens being ready for the global competition especially taking active participation in the Community of Asian Economy being effective since December 2015. In other words, the Ministry of Education and Culture has launched a modified curriculum called "Curriculum 2013" which are characterized by among others the following attributes: (1) implementing inquiry-based learning in which students are required to explore rather than to be spoon-fed by teachers; (2) promoting student active learning in which students are reinforced to be more active in learning to employ critical thinking.

\section{Teaching Models and Higher Order Thinking Skill (HOTS)}

Curriculum 2013 has mentioned some teaching models, such as Discovery learning, Problem-based learning, Projectbased learning, and so forth to be implemented by the teachers. Based on the questionnaires results, some teachers or most of the respondents did not implement those models in their teaching. Among the reasons, some teachers were confused to apply the models because of insufficient knowledge about the models.

According to Bruner (1961). Discovery Learning is a method of inquiry-based instruction, discovery learning believes that it is best for learners to discover facts and relationships for themselves.

Furthermore, Bruner mentioned that Discovery learning is an inquiry-based, constructivist learning theory that takes place in problem-solving situations where the learner draws on his or her own past experience and existing knowledge to discover facts and relationships and new truths to be learned. Students interact with the world by exploring and manipulating objects, wrestling with questions and controversies, or performing experiments. As a result, students may be more likely to remember concepts and knowledge discovered on their own (in contrast to a transmissionist model). Models that are based upon discovery learning model include guided discovery, problem-based learning, simulation-based learning, casebased learning, incidental learning, among others.

Proponents of this theory believe that discovery learning: a) encourages active engagement, b) promotes motivation, promotes autonomy, responsibility, independence, c) develops creativity and problem-solving skills, and d) tailors learning experiences.

The skill of HOTS in Taxonomy Bloom is thinking at a cognitive level. In the cognitive domain (Bloom, 1956). HOTS is at a level of analysis, synthesis, and evaluation. At the level of practice, teachers apply cognitive at the level of knowledge, comprehension, and application. It is clear that teachers have no experience to implement HOTS. Therefore, the responses of the respondents show that most of them have the knowledge, read about these cognitive domains but confused to implement them in their teaching.

Besides, the teachers' knowledge about HOTS, the condition of the students is another serious problem. The students of rural areas did not study the English language because it is not a compulsory subject. Some schools might have English subject as local content. When they studied at Junior High Schools, they have to study English at a certain level which is highly beyond their knowledge. On the other hand, HOTS is at a higher level of the cognitive domain. Thus, this problem becomes complicated which might be difficult to implement in the teaching-learning process.

Some ideas on creating a culture of thinking, such as (1) model thinking, (2) Allow thinking time, (3) Provide an opportunity for thinking, (4) Create a physical environment conducive to thinking, (5) Introduce thinking routines, (6) Show that you value thinking, (7) Give them something worth thinking about, (8) Let go, (9) Focus on big ideas, and (10) Focus on learning, not work (Ritchhart \& Perkins, 2005).

From the ten aspects mentioned, they are intended to create a culture of thinking. The first aspect, model thinking is a process of sharing ideas from a teacher and exploring some possibilities with students. This model allows some ideas come from the students. At the same time, the teacher should give some time for the students to think before a response to any questions as the second aspect "allow thinking time". The third aspect, provide opportunities for thinking, is a process of giving the opportunity to the students to explore their own experiences as the starting point of activating their ideas and prior knowledge. The fourth aspect, create a physical environment of conducive thinking, is dealing with some aspects of seat arrangement, formulate the rules of turn talking and determine members of a group. If the environment is suitable for them, it might be able to create an ease of communication. In order words, the smooth flow of communication among the members of the group will let the students explore more things or matters, then, it will enhance thinking.

Furthermore, it is necessary for a teacher to value any idea of the students. Valuing idea in terms of verbal, such as good or great are praises that may motivate the learners to produce more idea which in return encouraging thinking skill. The topic of discussion should be something worth thinking of, such as something beneficial for a living, future challenge, and other important matters. They will attract their attention to talk more because they think those matters are useful for their career, aims, and future life. Therefore, the discussion topic should activate the stimulus and create a strong provocation to involve or engage deeply with the topic.

In the teaching-learning process, the teacher tends to dictate their students think as he/she thinks without giving freedom in expressing one idea or opinion. In this situation, the students are directed to one destination, not for many destinations. This culture of guiding the students to think freely may not be created or developed. Therefore, the culture of giving an opportunity to talk freely should be encouraged or developed well among learners. Besides, the aspects of focus on big ideas and focus on learning are the two aspects which are inseparable because a focus on ideas is part of learning. The ideas or subject matter to be learned 
should be focused so that the students will understand well the matter being learned. In other words, learning needs to be focused on certain ideas or matter.

\section{CONCLUSIONS AND SUGGESTIONS}

\section{A. Conclusions}

The challenges of developing teachers' professionalism need proper planning and should be done continuously. The problems of the 2013 curriculum's implementation should go through sufficient training/workshops. From the results of questionnaires, therefore, the main conclusions are:

1. teachers' understanding of the vision and mission of the curriculum, and as well as the goals,

2. the understanding and application of teaching models are low,

3. the procedures of implementing the $21^{\text {st }}$-century skills are not well designed and prepared for the better operation.

\section{B. Suggestions}

In accordance with the conclusions above, there are some suggestions for improvement in the future, are:

1. give more training about the curriculum,

2. provide more workshops on the process of designing a syllabus, lesson plan, material development,

3. encourage teachers to read some regulations, Minister's Decree, and so forth,

4. need further research to search for better improvement and development in curriculum 2013.

\section{REFERENCES}

Anderson, L. W., and Krathwohl, D. R. (2001). A taxonomy for learning, teaching, and assessing. New York: Longman.

Ausubel, D. (1978). Educational Psychology: a Cognitive View Holt. Rhinehart and Winston.

Bloom, B. S. (Ed.) (1956). Taxonomy of educational objectives: The classification of educational goals. Handbook I, cognitive domain. New York: Longmans.

Bruner, J. S. (1961). The Act of Discovery. Harvard Educational Review, 31, 21-32.

Davies, Martin. (2017). Studies show that critical thinking is now more important than ever. http://explorist.futurism.com/studies-show-thatcritical-thinking-is-now-more-important-than-ever/. (Accessed on September 10 $0^{\text {th }}, 2018$ ).

Doyle, Alison. (2018). Critical Thinking Skills. http://www.state.nj.us/education/profdev/regs/def.p df (retrieved 10 September 2018).

Early, M. (2003). Critical Thinking Skill. English Quarterly, $35(1)$, 14-20. http://aguslistiyono.blogspot.com/2010/10/berpikirtingkat-tinggi-higher-order.html.

Fisher, A. (2008). Berpikir Kritis "Sebuah Pengantar". Jakarta: Erlangga.
Ritchhart, Ron, and Perkins, David N. (2005). Learning to Think: The Challenges of Teaching Thinking. Cambridge: Cambridge University Press.

UU RI. (2003). Undang-Undang Republik Indonesia Nomor 20 Tahun 2003 tentang Sistem Pendidikan Nasional. Jakarta: Kemensesneg.

UU RI. (2005). Undang-Undang Republik Indonesia Nomor 14 Tahun 2005 tentang Guru dan Dosen. Jakarta: Kemenkumham. 